\title{
GÊNERO, IDEOLOGIA E PERCEPÇÕES DE DIREITOS HUMANOS NO ENSINO BÁSICO
}

\author{
Ana Carolina Amaral de Pontes* \\ Wellington Cabral Saraiva**
}

\section{RESUMO}

A discussão sobre educação de gênero como conteúdo transversal gera debates entre parcelas de representações políticas e educacionais, utilizando como pano de fundo a disputa entre esferas pública e privada ao discutir o que seria temática doméstica e escolar. Refletir sobre as razões políticas que movem os atores, nos seus aspectos aparentes e nos essenciais, nem sempre visíveis, tornou-se premissa deste debate. Propõe-se a perspectiva de a educação ser locus privilegiado para acolhimento e prevenção de discriminação e violação de direitos humanos de grupos vulneráveis por desequilíbrios de gênero arraigados na sociedade brasileira.

Palavras-chave: Gênero; Escola; Ideologia; Discriminação; Educação.

\section{GENDER, IDEOLOGY AND HUMAN RIGHTS PERCEPTIONS IN PRIMARY SCHOOL}

\begin{abstract}
Discussion about gender inclusive education as a cross-cutting content in Brazilian schools generates strong debates amongst parts of political and educational representation. This paper takes into account the dispute between the public and private spheres when discussing what would be family and school themes. Reflecting on the political reasons that drive the actors of this debate, both in its apparent and essential aspects, not always visible, has become an assumption. Education is viewed as a privileged locus for protection and for preventing discrimination and violation of vulnerable groups' human rights because of gender imbalances deeply rooted in the Brazilian society.
\end{abstract}

Keywords: Gender; School; Ideology; Discrimination; Education.

\footnotetext{
*Professora Adjunta da Universidade Federal Rural de Pernambuco (UFRPE). Doutora em Educação pela Universidade Federal de Pernambuco (UFPE), Mestra e Especialista em Direito pela mesma universidade. E-mail: professoraanapontes@gmail.com. Endereço postal: Av. Bom Pastor, s/n, Boa Vista55292-270 Garanhuns (PE).

***Procurador Regional da República. Procurador Regional Eleitoral Substituto em Pernambuco. Ex-Coordenador da Assessoria Jurídica Constitucional do Procurador-Geral da República. Mestre em Direito pela Universidade de Brasília. E-mail: wsaraiva@gmail.com. Endereço postal: Rua Frei Matias Teves, 65, Paissandu - 50070-465 Recife (PE).
} 


\section{OBSERVAÇÕES INTRODUTÓRIAS}

Tendo como cenário candente certa dubiedade de conceitos na construção deste debate, a discussão de gênero e direitos nas escolas brasileiras tem alcançado espaço de disputa de significados preliminar à própria narrativa dos personagens envolvidos, sugerindo a necessidade premente de aumentar a visibilidade da temática. Este artigo partiu de pesquisas inspiradas por arguição de descumprimento de preceito fundamental (ADPF) proposta pela Procuradoria-Geral da República no Supremo Tribunal Federal em resposta a iniciativa legislativa de municípios para proibir discussões calcadas em gênero no âmbito escolar. A ADPF (com base no artigo 102, § 1ํㅡㄹ da Constituição da República e na Lei 9.882, de 3 de dezembro de 1999) ataca a Lei 2.243, de 23 de março de 2016, do Município de Palmas (Tocantins), relativa ao Plano Municipal de Educação. A lei incluiu meta que impede uso de material didático e paradidático sobre "ideologia ou teoria de gênero". 1

Esse material se somou a contribuições de pesquisas empreendidas por órgãos internacionais e informações específicas sobre a realidade brasileira de violações a direitos humanos, em confluência com o papel da escola como transformadora de percepções cristalizadas e como espaço de violação e de reprodução de discursos violadores dos direitos tocantes ao gênero. O ponto central da análise alcança o esclarecimento de conceitos que vêm sendo popularizados no esclarecimento das noções de ideologia, gênero e violações. Buscou-se responder à pergunta de qual sentido há em discutir gênero nas escolas e quais relações podem ser construídas a partir dessa visão. Discutem-se também de que forma a visão de gênero como ideologia milita a favor de uma visão ou de outra e os reflexos da disseminação dessa percepção. Até onde irão a autonomia de educandos e educandas e o poder familiar de mães, pais e grupo familiar responsável sobre essa autonomia e sobre a influência na escolha dos conteúdos escolares?

Como sustentar o discurso de fortalecimento para participação pública e autonomia que frequentemente é encampado como função da escola, de que ela estabeleça de forma equilibrada e justa como as pessoas podem definir seus caminhos com reflexos coletivos?

Discussão que não vislumbre reconhecimento do outro como sujeito não consegue estabelecer

\footnotetext{
${ }^{1}$ Este artigo se refere à ADPF 465/TO, proposta pelo Procurador-Geral da República no Supremo Tribunal Federal contra lei do Município de Palmas (TO). Normas análogas são discutidas nas ações diretas de inconstitucionalidade 5.537/AL e 5.580/AL, contra lei do Estado de Alagoas, e nas ADPFs 457/GO, 460/PR, 461/PR, 462/SC, 466/SC e 467/MG, contra leis dos Municípios de Novo Gama (GO), Cascavel (PR), Paranaguá (PR), Blumenau (SC), Tubarão (SC) e Ipatinga (MG).
} 
diálogo primitivo sequer de sua existência. Relembrando Van Gunsteren, “as ações próprias dos cidadãos são somente aquelas que tendem a manter, e passíveis de incrementar, o exercício da cidadania” (VAN GUNSTEREN, 1987, p. 26). Uma vez estabelecida como categoria de direito fundamental, a exemplo da democracia, a igualdade de gênero não apenas se expressa na garantia de direitos femininos e masculinos, mas em discussão mais ampla sobre o existir. A negativa ao debate implica um não existir dos próprios integrantes, que traz reflexos sobre a forma como as pessoas se relacionarão com os demais conteúdos escolares, mas não apenas: reflete-se nas relações de poder desenvolvidas na realidade escolar, desde o uso de espaços coletivos, como banheiros, refeitórios e salas de aula, entre outras dimensões.

É tema central deste artigo a necessidade de reflexão sobre quais conceitos têm permeado a discussão do que seja "ensinar gênero" (caso possível fosse) nas escolas, o que vem sendo compreendido como "ideologia de gênero", e quais as perspectivas de franquear a discussão sobre as percepções coletivas e individuais de gênero e suas construções no espaço educativo. Tal visão tem por objetivo trazer análise que contribua para ampliar as discussões sobre direitos humanos no espaço escolar e em especial apontar a importância desta discussão para prevenir violações de direitos no espaço escolar e fora dele. A temática mostra-se fortemente necessária, justificada tanto pelas recentes discussões e eventos como por frequentes ações buscando afastar a discussão sobre gênero dos conteúdos escolares, seja mediante condenação do uso de material didático que o suscite até a promulgação de inúmeras leis municipais e estaduais que pró́bem essa abordagem em sala de aula e, surpreendentemente, sugerem até punições para docentes. Percebe-se ofensiva crescente via patrulhamento de suposta neutralidade ideológica a fórceps na docência de primeiro e segundo graus em temáticas pertinentes a gênero e ao exercício de sexualidade por meio de projetos de lei e supressões de currículos. O problema consiste em investigar a clareza dos conceitos em jogo e as ligações entre a ausência deste debate nas escolas para os desdobramentos possíveis no não fortalecimento de aspectos importantes de direitos humanos. 


\section{LEGISLAÇÃO ESTADUAL E MUNICIPAL PARA OBSTAR A DISCUSSÃO DE GÊNERO: USURPAÇÃO DE COMPETÊNCIA DA UNIÃO}

Capitaneadas em parte significativa por discursos de aspecto religioso, evocando tradições familiares e a existência de papéis predeterminados que confundem gênero com orientação sexual, atração física e atração afetiva, a incipiente inclusão de discussões de gênero de forma nacional encontrou resistência pulverizada em diversas iniciativas legislativas municipais e estaduais e falta de clareza dos conceitos em jogo e das ligações entre a ausência desse debate nas escolas para o não fortalecimento dos direitos humanos. Antes de adentrar as especificidades da polissemia vigente, utilizar-se-á o caso do Município de Palmas como fio condutor para desvelar a amplitude do tema. A Lei 2.243/2016, desse município, veda discussão e utilização de material didático e paradidático sobre "ideologia ou teoria de gênero" e promoção e condutas, permissão de atos e comportamentos que "induzam à referida temática, bem como os assuntos ligados à sexualidade e erotização". A norma padece de inconstitucionalidade e de problemas do ponto de vista da construção de conhecimento sobre tolerância e diversidade.

As normas da lei de Palmas não são exceção. Seguem fluxo iniciado nacionalmente, com nuanças de cruzada e consubstanciado em projetos de leis de numerosos municípios e de alguns estados, o que também demonstra tornar-se temática que implica problemas de segurança jurídica. Proibir educação para compreensão da diversidade de gênero apresenta potencial para gerar dificuldades substanciais no sistema jurídico, uma vez que decisões contraditórias podem ser tomadas no controle de constitucionalidade de leis municipais e estaduais pelos estados-membros.

De início, portanto, no aspecto formal, a "municipalização" da competência para decidir conteúdos transversais de extrema relevância para o espaço educativo é não apenas um gigantesco ralo para insegurança jurídica na matéria mas implica, também, retirar força indispensável da atuação dos conselhos municipais, estaduais e nacionais de educação e ignorar de forma absolutamente descompromissada os saberes específicos de educadoras e educadores que compõem secretarias, ministérios e sala de aula. Promove verdadeira "judicialização" de hierarquização ou supressão de conteúdos por meio da representação legislativa. A lei contraria preceitos fundamentais da Constituição da República concernentes ao objetivo constitucional de 


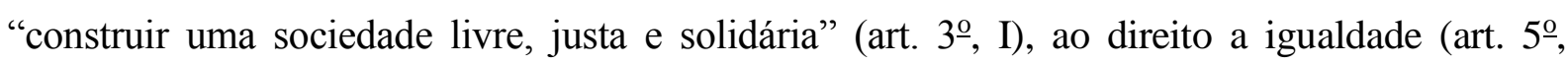
caput), à vedação de censura em atividades culturais (art. 5º, IX), ao devido processo legal substantivo (art. 5º, LIV), à laicidade do estado (art. 19, I), à competência privativa da União para legislar sobre diretrizes e bases da educação nacional (art. 22, XXIV), ao pluralismo de ideias e de concepções pedagógicas (art. 206, I) e ao direito à liberdade de aprender, ensinar, pesquisar e divulgar o pensamento, a arte e o saber (art. 206, II).

Mesmo observando apenas o aspecto formal, normas municipais como a aprovada em Palmas, ao vedar discussão e uso de material didático e paradidático sobre "ideologia ou teoria de gênero", usurpam competência privativa da União para legislar sobre diretrizes e bases da educação nacional (CR, art. 22, XXIV). Por conseguinte, afrontam o pacto federativo. Cabe à União, a estados e ao Distrito Federal competência concorrente para regular "educação, cultura, ensino, desporto, ciência, tecnologia, pesquisa, desenvolvimento e inovação" (art. 24, IX). Em relação aos municípios, a competência é apenas suplementar e deve atender ao princípio do interesse local, em consonância com as diretrizes fixadas pela União. Sua definição em cada município pode ser flexibilizada para incluir (até porque há discussões sobre aspectos locais de relevância, mas a própria legislação educativa nacional prevê a possibilidade desses acréscimos), jamais para suprimir. Definições sobre diretrizes de educação são centrais nos processos de ensino. Não podem ser definidas em cada município do país.

A competência privativa da União para legislar sobre diretrizes e bases da educação nacional já foi reconhecida pelo Supremo Tribunal Federal e, no exercício dessa competência constitucional, o ente central da federação editou a Lei 9.394, de 20 de dezembro de 1996 (Lei de Diretrizes e Bases da Educação Nacional- LDBEN ou LDB), a qual pauta o ensino, entre outros, nos princípios da liberdade de aprender, ensinar, pesquisar e divulgar a cultura, o pensamento, a arte e o saber, no pluralismo de ideias e de concepções pedagógicas e no respeito à liberdade e apreço à tolerância (art. 3ํㅜㅇ II a IV).

Ao instituir, em sistema de educação municipal, proibição de referência a discussões sobre identidade de gênero e diversidade sexual e mesmo ao intuir, com certa obrigatoriedade para docentes, repressão a condutas que sugiram liberdade de identidade de gênero, a Lei 2.243/2016 invade competência da União e busca transformar parte da docência em censora involuntária, ainda que outra porção possa se regozijar com a tarefa de imiscuir-se em competências para censura de comportamentos que em nada se ligam à 
disciplina em sala de aula e que, decididamente, competem ao escrutínio pessoal e ao bem-estar existencial da educanda ou educando.

\section{GÊNERO: IDENTIDADE OU IDEOLOGIA? A PROPOSITAL POLISSEMIA REINANTE E A NEGAÇÃO DE DIREITOS FUNDAMENTAIS}

Diferenciação entre sexo e gênero propicia rompimento com o determinismo da natureza no campo da sexualidade e da identidade. É importante reforçar esse aspecto, porque as iniciativas legislativas não buscam, exclusivamente, supressão do debate, como é publicizado com frequência. Almeja-se também aderência do professorado ao conceito binário de cissexualidade e mesmo a inesperada responsabilização da autoridade docente na repressão de condutas que escapem, a qualquer pretexto, dessa visão.

O sexo (e não se fala do exercício da sexualidade) é dimensão eminentemente biológica, ao passo que gênero é conceito a envolver componentes culturais, sociológicos, psicológicos e de outras ordens. Ainda assim, o gênero, sozinho, não define orientação sexual ou impulsos afetivos humanos. Estudos de gênero são disciplina que toma a desnaturalização do feminino e masculino biológicos como percepção única e admite a fluidez dos conceitos de identidade e orientação sexual e afetiva. Exemplo interessante, mas não excludente ou definitivo, é a discussão sobre "cisgênero" e "transgênero", expressões a definir pessoas que se identificam com o gênero atribuído ao nascer (cisgêneros) e aquelas que não vivenciam essa identificação (transgêneros) e que constituem uma das situações alvo de violação de direitos das leis municipais.

A partir do momento em que proposital ou descuidadamente se ignoram as inúmeras variantes de identidade de gênero, de orientação sexual e de orientação afetiva, permite-se invisibilização do sujeito e abre-se grave espaço para sua exotização ou negação. O grupo social - em especial em etapa de profunda vulnerabilidade emocional, como no período escolar, em que o espaço semipúblico da escola se encontra no simulacro de transição entre a esfera privada do lar e a pública da ágora humana - pode ser deformante e constrangedor quando autoriza indiscriminadamente o "direito" de estrangulamento da autodescoberta.

A Lei 2.243/2016 vai além: como outras, utiliza indevidamente a expressão "ideologia de gênero" (de conteúdo incerto e que constitui, ela própria, manifestação 
ideológica, diferentemente da identidade de gênero, que é manifestação da subjetividade pessoal calcada na essência humana individual, apartada do território das escolhas) para legitimar fusão artificial entre gênero e interesses. Uma mera inclinação poderia ser direcionada no processo educativo, o que em absoluto não condiz com a realidade. Sob a alegação de que identidade de gênero seria um comportamento (confundindo com orientação sexual e orientação afetiva), gera-se perigoso efeito reverso do que prioritariamente deveria ser preservado: a discussão da temática do direito a identidade pessoal e do respeito à diferença, peça fundamental do campo dos direitos e do processo educativo.

De forma escamoteada ou escancarada, como no fato de lobbies constantes em rádios de controle de religiões neopentecostais contra o debate sobre identidade de gênero nas escolas, ideologia serve como palavra-disfarce. É discriminatória, porquanto também violadora da laicidade do estado, pois parte significativa de seus argumentos é de origem religiosa. Colide com os direitos fundamentais à igualdade, à liberdade de ensino e de aprendizado, à proteção contra censura e à liberdade de identidade de gênero, decisão sobre exercício pessoal futuro ou presente de sexualidade e orientação sexual e afetiva.

A vedação que a Lei 2.243/2015 introduz nas estratégias 5.24 e 5.26 da Meta 5 do Plano Municipal de Educação de Palmas - de "discussão e utilização de material didático e paradidático sobre a ideologia ou teoria de gênero, inclusive promoção e condutas, permissão de atos e comportamentos que induzam à referida temática, bem como os assuntos ligados à sexualidade e erotização" - é propositadamente aberta, pois não há delimitação clara do que seja "ideologia de gênero", seja na própria lei, seja em fontes fiáveis.

Tomar ideologia como sinônimo de teoria demonstra que a pretensão é criar ente nebuloso para vedar qualquer abordagem de temas ligados à sexualidade que não seja para reafirmar uma inexistente equivalência entre sexo e gênero e para ignorar quaisquer realidades distintas do marco heteronormativo. Mesmo a chamada "teoria de gênero" constitui somente o estudo de fenômeno que não influencia: apenas o analisa. Não existe especificamente uma teoria de gênero, mas teorias que, estudando as manifestações de identidade humana relacionadas ao gênero, admite existência de fluidez e variante mais ampla do que o marco heteronormativo no qual fragilmente as legislações tentam se ancorar para justificar o injustificável direito de violar a individualidade humana como parte de um suposto projeto para garantir a existência coletiva da sociedade. 
Em entrevista, Jimena Furlani (2016) doutora em Educação, aponta o uso do conceito indeterminado "ideologia de gênero" como forma de tolher a abordagem, nos planos de educação, das diferentes manifestações da sexualidade e impedir qualquer debate sobre gênero, orientação sexual, diversidade sexual, nome social e educação sexual. A supressão desses termos dificulta o trabalho dos educadores e lança ameaça difusa sobre eles. A visão é míope e perversa, porque a exclusão desses temas não os elimina da vida nem evita - antes agrava - os conflitos pessoais e interpessoais a eles relacionados.

Não é epistemologicamente aceitável falar em "ideologia de gênero" pela simples razão de que gêneros não possuem ideologia. A expressão tenta associar o termo "ideologia", com caráter depreciativo. Mais: tenta reforçar o conceito já profundamente desacreditado de que expressões da sexualidade (por exemplo, embora não se restrinjam a isto) sejam "adestráveis" para supostos consertos de correspondência entre biologia, gênero e sexualidade. Tal situação já ensejou violações gravíssimas que remontam ao nazismo, aos gulags, aos campos da Chechênia e a inúmeras violências na esfera cotidiana, incluindo crianças e jovens cruelmente mortos por pais e mães por apresentarem o que supunham como desvio desse marco. $^{2} \mathrm{O}$ padrão heteronormativo viola identidades e afetos e promove eliminação de vidas, tanto na perspectiva macroestatal quanto na das pequenas violências cotidianas, até os extremos da negação do direito ao existir.

Não se pode acatar a visão dissociada da realidade de que gênero corresponda necessariamente a sexo e que, por isso, somente existam os gêneros masculino e feminino, pois seriam os únicos surgidos da natureza. Mesmo do ponto de vista biológico, há conformações biológico-anatômicas distintas dos modelos costumeiramente associados a homens e mulheres, como é o caso dos hermafroditas e das demais manifestações de intersexualidade. Falar em gênero como resultante de ideologia é impropriedade mesmo do ponto de vista da Biologia e da Genética, e muito mais do de outras áreas do conhecimento humano, como a Sociologia e a Psicologia. A argumentação da "ideologia de gênero" é profundo contrassenso: quando se trata do que identifica como "desvio" da heteronormatividade, é caso de ideologia adotada pelo estudante vulnerável à "má influência", a ser zelada e corrigida pelo professor ou professora. Se gênero fosse ideologia, forçosamente se teria de admitir que o gênero masculino ou feminino também não é "natural" como o discurso prega, mas construído. Ser biologicamente homem e comportar-se como homem não

${ }^{2}$ Vide, entre outras, a notícia Mãe confessa assassinato de filho adolescente no interior de SP. 
seria tão "genuíno" ou "natural" como a campanha das legislações municipais sugere, mas fruto de ideologia. Tão "mutável" como ser biologicamente homem e identificar-se como mulher, por exemplo. Afinal, a regra não deveria poder ser flexibilizada ao gosto do freguês.

O conceito parte de falácia segundo a qual educadores e educadoras que defendem incluir a discussão de gênero e sexualidade em sala de aula, nomeados e nomeadas por opositores como partidários da "ideologia de gênero", sustentariam que a conformação biológica natural seria irrelevante e que as pessoas construiriam o próprio gênero por ato de vontade. Seria urgente impedir que crianças e adolescentes tivessem acesso a discussões em sala ensejadoras da reflexão de existirem mais "opções" do que a esfera feminina e a masculina. Justificam o receio de que materiais e abordagens didáticas com discussão sobre gênero, manifestações de sexualidade e orientação sexual e afetiva poderiam induzir crianças e adolescentes a optar por gêneros distintos do que se costuma corresponder à associação biológica tradicionalista (quando não houver intersexualidade) e até a se engajarem em práticas sexuais incompatíveis com sua idade e maturidade (o que é absurdo, porquanto identidade de gênero não se confunde com exercício de sexualidade nem com orientação sexual; a visão nublada impede abordar o relevante tema das pessoas assexuais). A atribuição de que docentes poderiam agir com a finalidade de definir o gênero de educandas e educandos independentemente da conformação biológica destes é de simplicidade e erronia primários. Felipe Aquino (2015), por exemplo, conhecido militante católico contra a "ideologia de gênero", aponta que ela é "uma ideologia subversiva que derruba o Direito natural, desconstrói a pessoa, desnorteia a criança, destrói a família, o matrimônio e a maternidade; e, deste modo, fomenta um 'estilo de vida' que incentiva todas as formas de experimentação sexual desde a mais tenra idade; inclusive a pedofilia e o incesto, defendidos sorrateiramente pela Simone de Beauvior (sic) e outras feministas".

Tratar do gênero como realidade humana, inclusive nas escolas, não implica nem deve implicar interferências na individualidade da identidade de gênero, na construção das manifestações de afetividade ou supressão da reflexão sobre a sexualidade. Não se traduz em incetivo à precocidade de práticas sexuais. Pelo contrário, refletir sobre gênero e sexualidade permite que a sexualidade seja dimensionada no espaço temporal adequado, com tranquilidade, maturidade e prevenção. A abordagem, bem ao contrário, deve servir para expandir a cultura de respeito à diversidade, à identidade, aos direitos fundamentais e discussão fundamental, nublada quase por completo no atual debate: a indispensável, adiada e 
forte raiz da realidade brasileira de manutenção de sociedade patriarcal, machista e tolerante à violência simbólica, cotidiana e grave contra a mulher, que se consubstancia desde a sutil construção de que as meninas (as quais incorporam esse discurso) sejam menos capazes em determinados conteúdos e disciplinas; até o habitual julgamento das vítimas de estupros e feminicídio que infestam os comentários de portais de notícias.

\section{DIREITO HUMANO, IDENTIDADE DE GÊNERO E EQUIDADE DE GÊNERO}

Segundo a Constituição da República, todos são iguais perante a lei, sem distinção de natureza alguma (embora algumas distinções sejam inerentes à realidade e possam servir para gerar igualdade material). A norma de seu art. 5 enuncia a "virtude soberana" preconizada por Ronald Dworkin (2005) de um estado, o princípio da igualdade, o qual, com o princípio da liberdade, forma um dos pilares do estado constitucional. A igualdade também está assegurada, entre outros importantes instrumentos, na Declaração Universal dos Direitos Humanos, na Convenção Americana sobre Direitos Humanos (o conhecido Pacto de São José da Costa Rica, promulgado pelo Decreto 678, de 6 de novembro de 1992) e no Pacto Internacional sobre Direitos Civis e Políticos (promulgado pelo Decreto 592, de 6 de julho de 1992).

Também os Princípios de Yogyakarta ${ }^{3}$ tratam da isonomia e especificamente da não discriminação por motivações de gênero, ao proscrever distinção, exclusão, restrição ou preferência baseada na orientação sexual ou identidade de gênero que tenha o objetivo ou efeito de anular ou prejudicar a igualdade perante a lei ou o reconhecimento, gozo ou exercício, em base igualitária, de todos os direitos humanos e das liberdades fundamentais (vide Princípio 2).

O Supremo Tribunal Federal produziu importante precedente relativo à proibição de discriminação em razão de sexo e gênero, na ação direta de inconstitucionalidade (ADI) 4.277/DF, quando julgou a validade da união homoafetiva como instituto jurídico. O relator, Ministro Ayres Britto, ressaltou a proibição constitucional de discriminar pessoas em razão do sexo, do gênero e da orientação sexual, da liberdade individual para dispor sobre a própria

\footnotetext{
${ }^{3}$ Embora não se trate de norma de direito internacional, os princípios de Yogyakarta (cidade da Indonésia) foram aprovados em conferência organizada pela Comissão Internacional de Juristas na Indonésia, em novembro de 2006. Disponíveis em $\quad$ http://migre.me/wD6rp $>$ ou < http://www.clam.org.br/uploads/conteudo/principios_de_yogyakarta.pdf >; acesso em 17 maio 2017.
} 
sexualidade, até como manifestação da autonomia da vontade, e da impossibilidade de tomar o sexo como fator de desigualação jurídica, salvo diante de disposição constitucional expressa. $\mathrm{O}$ julgamento da ADI contém outros importantes padrões hermenêuticos, como a inserção isonômica de núcleos heteroafetivos e homoafetivos no conceito constitucional de família.

Se gênero é categoria que concorre para explicar a identidade humana e se a diversidade sexual e afetiva se apresenta em diversas orientações, a busca por equidade mediante igualdade de gênero perseguida pela Constituição proíbe qualquer forma de discriminação lesiva. A Lei 2.243/2016 de Palmas fere o constitucionalismo quando viola a igualdade e busca obstar a própria discussão pedagógica do tema. Ao vedar que qualquer dimensão do ensino trate de temas de gênero, reforça o paradigma heteronormativo e rejeita a diversidade sexual, que é fato da vida, independentemente da vontade e das concepções de religiosos, legisladores, demais agentes públicos e de quem quer que seja.

A arguição de descumprimento contra a lei palmense cita pesquisa de Lionço e Diniz (2009, p. 52), que analisaram o conteúdo de livros didáticos e observam o caráter não só heterossexual, mas heteronormativo da sociedade, que se manifesta em livros didáticos nas representações de gênero e das organizações familiares, na ausência do tema da diversidade sexual, na associação da sexualidade à dimensão biológica e reprodutiva e na excepcionalidade da diversidade sexual nas obras literárias. Isso condiciona crianças e adolescentes a olhar o universo social de forma dicotômica e reproduz o padrão. O silêncio serve como estratégia discursiva dominante e torna nebulosa a fronteira entre heteronormatividade e homofobia.

O que é ensinado nas escolas depende em grande medida do conteúdo dos livros didáticos. A relação é mútua, pois professores e professoras participaram nos últimos governos brasileiros de diversas votações para escolhas dos livros didáticos que usariam. Ao excluir o ensino sobre temas ligados ao gênero, a norma atacada e suas homólogas afrontam não apenas o direito fundamental à educação de estudantes e professores, como violam os direitos de quem esteja fora do padrão heteronormativo (como a população LGBT) de ter seu corpo, sua sexualidade, sua realidade e seus dilemas representados nos livros e abordados nas escolas. Tais normas são obscurantistas, porque almejam proscrever o próprio debate sobre uma realidade humana. Ao sonegar dos estudantes e das estudantes a discussão sobre temas concernentes a sexualidade, afetividade e gênero, contribuem para perpetuar a cultura de violência, tanto psicológica quanto física, contra vastas parcelas da população LGBT do país e 
a cultura de subalternização do gênero feminino, deslocando como horizonte inatingível a equidade de gênero, com o que se distanciam do objetivo constitucional de "construir uma sociedade livre, justa e solidária" (art. 3ํㅗ I).

Elas, todavia, perigosamente não se restringem a isso: reforçam estereótipos sobre papéis predeterminados de gênero mesmo entre estudantes que se encontram supostamente dentro da correspondência entre biologia e identidade de gênero, pois sua visão espera muito mais do que identificação com o sexo biológico. Supõe adesão a um conjunto de normas sociais que secularmente coloca a mulher em posições de subalternidade, menos-valia e submissão ao homem, o que naturaliza situações de violência que acompanharão meninos e meninas no futuro em posturas de masculinidade tóxica e feminilidade amputante.

\section{REPRESENTAÇÕES LEGISLATIVAS, VEREADORAS A SERVIÇO DA DESIGUALDADE E PODER FAMILIAR: A VOZ DO POVO É A VOZ DE DEUS?}

A concepção de cidadania ativa, como incremento da diversidade e eficiência da instrumentalização da participação nos processos de formação do poder, viabiliza o que se pode chamar de exercício da democracia participativa em um estado democrático de direito. Há várias razões pelas quais é possível compreender o caráter limitante da democracia representativa atual. Aqui se exporão apenas reflexões preliminares das limitações que o processo democrático atual carrega, como forma de explicitar o alcance negativo de estabelecerem-se amarras de gênero, em dinâmica representativa por si já discutível.

Em um processo de identificação "autoral" das regras, como se citou, a capacidade representativa permanece física e não raro ideologicamente distante dos/as representados/as, sendo este apenas um dos aspectos relevantes. Hannah Arendt comenta serem as cabines em que depositamos as cédulas "muito pequenas" onde "só tem lugar para um". Observando a ignorância do eleitorado que apoia os proponentes da legislação mencionada, tal reflexão reflete a importância de mecanismos mais amplos para assegurar representatividade (ARENDT, 2004, p. 200). Essa ignorância não é classificação rasa e ofensiva do eleitorado, mas a percepção, no próprio discurso dele, de que não dispõem de dados concretos para compreender o que é promovido ou proibido em sala de aula e de que se valem, muitas vezes, apenas da informação truncada e discutível repassada pela representação política nas câmaras municipais. 
Mesmo a liberdade da família de oferecer aos filhos educação religiosa e moral segundo suas convicções (art. 12, item 4, da Convenção Americana sobre Direitos Humanos) é limitada pelos princípios e objetivos da educação, dispostos no art. 13, item 1, do Pacto Internacional sobre Direitos Econômicos, Sociais e Culturais (PIDESC), 4 pelos padrões mínimos de ensino aprovados e prescritos pelo estado e pelos princípios constitucionais que conformam esse direito fundamental. Entre eles se destaca a liberdade de aprender, ensinar, pesquisar e divulgar o pensamento, a arte e o saber e o pluralismo de ideias e concepções pedagógicas (CR, art. 206, II e III).

Frequentemente, o discurso dos proponentes se reveste de inspiração religiosa e seus redutos eleitorais se fortalecem por uma política de fidelização à própria causa religiosa. Todavia, poucas vezes esse discurso incorpora claramente aceitar a violação das identidades: esta ocorre pela proposital subjetividade deixada nos conceitos excessivamente abertos das leis. Pais e mães entendem que seus valores não devam ser violados, mas não necessariamente apoiam que outras famílias se devam submeter à mesma axiologia (a despeito do forte proselitismo que caracteriza religiões neopentecostais). Isto, em princípio, seria mais compatível com a possibilidade de aceitar a diversidade de visões e manter o espaço de diversos discursos do que com a proposta que termina por se consolidar. Um exemplo entre inúmeros possíveis é notícia recente de um sítio eletrônico evangélico segundo o qual a bancada de parlamentares federais evangélicos estaria a pressionar o Ministério da Educação para alterar decreto apenas pelo fato de este preconizar como competência de uma de suas diretorias “desenvolver programas e ações transversais de educação em direitos humanos e cidadania nos sistemas de ensino que visem ao respeito à diversidade de gênero e orientação sexual, ao enfrentamento da violência, ao desenvolvimento sustentável, à superação das situações de vulnerabilidade social e ao combate a todas as formas de discriminação na escola". ${ }^{5} \mathrm{O}$ decreto seria forma sorrateira de introduzir a "ideologia de gênero" nas escolas. ${ }^{6}$ Iniciativas semelhantes são adotadas por organizações católicas ${ }^{7}$ e de outras denominações religiosas.

Laicidade do estado é princípio que garante pluralismo moral e protege minorias contra pretensões homogeneizantes de comunidades religiosas. Reforça as fronteiras entre as

${ }^{4}$ Promulgado pelo Decreto 591, de 6 de julho de 1992.

${ }^{5}$ Art. 25, II, do Decreto 9.005, de 14 de março de 2017, que aprova a estrutura regimental e o quadro demonstrativo dos cargos em comissão e das funções de confiança do Ministério da Educação.

${ }^{6}$ Bancada evangélica pede alteração do decreto assinado por Temer sobre "ideologia de gênero".

${ }^{7}$ Notícia da Arquidiocese do Rio de Janeiro relata uma dessas mobilizações e convoca para audiência pública a fim de discutir o Plano Municipal de Educação e pressionar pela exclusão de referências à "ideologia de gênero" (Católicos dizem não à Ideologia de Gênero no Plano Municipal de Educação). 
esferas pública e privada. Garante que os indivíduos professem suas crenças nos limites de sua vida privada e que o estado não interferirá para reprimir nem para privilegiar religião alguma. Marcelo Neves salienta o princípio de não identificação das constituições com visões totalizadoras de mundo (2011, p. 72-74). Se adotassem visões totalizantes como amiúde são as de cosmovisões religiosas, as constituições não poderiam gerar "complexidade interna adequada ao ambiente hipercomplexo" da contemporaneidade, dado que possuem a pretensão de valer para todos os domínios e mecanismos sociais.

Cidadãs e cidadãos, garantidos pelas liberdades individuais, encontram-se livres para adotar, manter e abandonar suas convicções, religiosas ou não, e podem transmiti-las e divulgá-las publicamente, desde que não firam ou contrariem direitos fundamentais de outrem. O estado, contudo, não possui essa garantia. Não deve adotar, manter nem fazer proselitismo de crença religiosa. O princípio da laicidade impede-o de promover, por atos administrativos, legislativos ou judiciais, juízos sobre o grau de correção e verdade de uma crença e de conceder tratamentos privilegiados a determinada concepção de fé ou de causar agravos a pessoas pelo fato de adotarem posturas distintas das de determinadas correntes religiosas. Também estabelece outra proibição para o estado: a impossibilidade de valer-se de critérios religiosos para condicionar o exercício de outros direitos fundamentais, como a liberdade de orientação sexual.

À parte as conhecidas discrepâncias sociais brasileiras e sua influência no processo representativo, no modelo democrático a partir da Constituição de 1988, já se encontravam previstas a gradual instalação de conselhos e a crescente participação da sociedade civil na tomada de decisões coletivas, o que aqui se demonstra como uma das alternativas para a amplitude da diversidade, inclusive de crença. Representações políticas e aumento do espectro de democracia participativa e esfera decisória em diversas esferas precisam contar com representações diversificadas para ampliar e fortalecer a participação popular na vida pública.

Nesse espaço, como se estrutura a fala pública? A esfera pública pode ser considerada espaço em que demandas e reivindicações se exteriorizam; com origem estatal ou não, traduzem-se em espaço do agir público e coletivo, visando interesses comuns. O espaço público, acrescenta Arendt, transcende "o ciclo vital das gerações [...] constituindo-se na memória e no capital de um povo". Mesmo a igualdade, necessária no espaço público, consiste em igualdade de desiguais, que, a despeito de suas particularidades, atuam sob a 
necessidade de serem considerados iguais sob certos aspectos e por motivos específicos (ARENDT, 1987, p. 257).

Retoma-se a discussão anterior na correspondência entre lideranças políticas, eleitores e eleitoras na discussão do falar com ao falar por. Vê-se aqui, novamente, uma espiral perversa: é comum a opção pelo falar por, calcada na dificuldade de identificar o espaço de opressão, frequente entre mulheres neopentecostais (a exemplo de vereadoras que vem abocanhando o eleitorado pernambucano, como Michele Collins e Irmã Aimée). Não apenas essa ausência de qualificação crítica decorre em parte de lacunas na educação formal (e isso leva a pensar que perversamente se reduzem ainda mais os espaços de discussão: "ideologia de gênero", "escola sem partido" etc.), o discurso de apartidarismo e "rejeição de ideologias" na verdade busca padronizar determinada ideologia como supostamente neutra e "natural", pois divina e supostamente biológica e agudiza esses abismos de compreensão. Se há queixas sobre falta de crítica, de interesse e de percepção da importância de participação social, esses discursos se tornam especialmente eloquentes quando fortalecem argumentosespantalho, como o suposto desinteresse feminino pela política quando se trata de afirmar os próprios direitos e não de paradoxalmente, como no tema deste artigo, aparentemente militar contra eles.

Caso emblemático é o da reeleição da autointitulada "missionária" Michele Collins, com altas votações, à Câmara Municipal do Recife. ${ }^{8}$ Ela representa proeminência feminina efêmera, ainda mais afastada ao reafirmar submissão à autoridade masculina (pai, marido, pastor), que apenas tende a provocar sensação de "conformidade" indispensável em seu eleitorado. A simples existência feminina não constitui afirmação mágica de consciência de gênero e de suas necessidades.

Formação de massa crítica feminina no eleitorado e na representação é fundamental e capaz de transformar a política mediante incorporação de temas relacionados a direitos e interesses das mulheres, em especial porque, repita-se, votar em certas pautas não corresponde a propô-las. É reduzido criticar propostas que agravam as desigualdades de gênero como esta julgando-as construídas por representantes políticos homens. Muitos legisladores homens não apenas carecem de sensibilização para votar em pautas femininas como também para criá-las, mediante proposições legislativas, ainda que eleitos por mais da metade de mulheres. A mera

\footnotetext{
${ }^{8} \mathrm{~A}$ própria identifica-se em sua página pessoal na internet como "Esposa do Pr. Cleiton Collins, mãe, três filhos, defende a família e a vida, serva e filha do Deus altíssimo e vereadora do Recife, pela misericórdia de Deus". Disponível em < http://www.michelecollins.com.br/biografia >; acesso em 6 mar. 2017.
} 
existência de mulheres eleitas não soluciona o problema, pois se busca não apenas representação feminina, mas representação por mulheres que tenham consciência dessas distorções, que proponham tais pautas e que sejam capazes de avaliar que a desigualdade de gênero, como traço estrutural, precisa de soluções coletivas e não pontuais. Fecha-se o ciclo: como construir essa visão crítica de homens e mulheres se a discussão foi suprimida dos espaços de educação formal?

\section{PLURALIDADE NA EDUCAÇÃO E CONSTRUÇÃO DE JUSTIÇA SOCIAL: INFLUÊNCIAS ENTRE SILENCIAMENTO DE GÊNERO, AFETIVIDADE, SEXUALIDADE E VIOLAÇÕES DE DIREITOS HUMANOS}

Os arts. 205 e 206 da Constituição da República estabelecem objetivos e princípios que integram o direito fundamental à educação, o qual deve visar a "pleno desenvolvimento da pessoa, [a] seu preparo para o exercício da cidadania e [à] sua qualificação para o trabalho". A Constituição concebe educação como preparação para exercício de cidadania, respeito a diversidade e convívio em sociedade plural, com múltiplas expressões religiosas, políticas, culturais e étnicas. Os objetivos de uma educação democrática estão expressos no Pacto Internacional sobre Direitos Econômicos, Sociais e Culturais ${ }^{9}$ e no Protocolo Adicional à Convenção Americana sobre Direitos Humanos em Matéria de Direitos Econômicos, Sociais e Culturais (Protocolo de São Salvador - promulgado pelo Decreto 3.321, de 30 de dezembro de 1999). Os objetivos externados no PIDESC (desenvolvimento da personalidade, dignidade humana, respeito pelos direitos fundamentais) e no Protocolo de São Salvador (sobre conteúdo da educação democrática e pluralista) não podem ser ignorados por escolas privadas e confessionais.

Não prospera o argumento de que proibir documentos de educação que abordem temas de gênero significa apenas transferir a escolha sobre onde deva ocorrer a discussão acerca de identidade de gênero, equidade entre gêneros e educação sexual. Educação democrática permite que o estado defina conteúdos de cursos de formação e objetivos do ensino, em alguma medida até de forma independente dos pais, sem significar redução da ascendência familiar na transmissão de valores e na formação de seus descendentes.

\footnotetext{
${ }^{9}$ Vide nota 6.
} 
O Tribunal Constitucional Alemão analisou se introduzir a disciplina Educação sexual em escolas públicas de ensino fundamental violaria a Lei Fundamental alemã, que assegura aos pais o direito de assistir e educar os filhos. Decidiu que a competência estatal para fiscalizar escolas abrange planejamento e organização do ensino, com o objetivo de garantir sistema escolar que ofereça possibilidades de formação na atual vida social, inclusive mediante fixação de conteúdos e objetivos escolares. O estado pode perseguir objetivos educacionais, em princípio independentemente dos pais. A função da escola de formar e educar crianças encontra-se no mesmo patamar do direito de educar da família e não se limita à transmissão de conhecimentos, mas busca transformar cada criança em membro responsável da sociedade. Sem desconsiderar que o lugar adequado para educação sexual individual seja o lar, a sexualidade apresenta diversas referências sociais. $\mathrm{O}$ estado pode reputar a educação sexual como importante elemento da educação total dos jovens, inclusive para alertá-los contra ameaças de cunho sexual (SCHWABE \& MARTINS, 2005, p. 508). ${ }^{10}$

O direito da família à educação de filhas e filhos cede em parte diante da missão constitucional do estado na área da educação. O direito assegurado a mães e pais de que seus filhos e filhas recebam educação religiosa e moral segundo as próprias convicções não se deve sobrepor aos princípios de educação democrática e pluralista.

A UNESCO recentemente apontou a necessidade premente de discutir gênero na escola, como forma de prevenção a violências presentes e futuras, tanto no ambiente escolar como na sociedade. Para o organismo, "aprofundar o debate sobre sexualidade e gênero contribui para educação mais inclusiva, equitativa, e de qualidade; não resta dúvida sobre a necessidade de a legislação brasileira e os planos de educação incorporarem perspectivas de educação em sexualidade e gênero.

$\mathrm{O}$ art. $3^{\mathrm{o}}$ da Lei de Diretrizes e Bases da Educação Nacional inclui nos princípios do ensino nacional o respeito à liberdade, o apreço à tolerância e o pluralismo de ideias e concepções pedagógicas. Permitir que escolas abordem conteúdos ligados a gênero e orientação sexual não se contrapõe ao papel da família: os valores e concepções que esta possa discutir complementarão o processo pedagógico do ambiente escolar e o auxiliarão a construir convicções que, espera-se, sejam identitárias.

Se a igualdade é virtude soberana de um estado, a vida de todos e de cada um importa. Todos os corpos precisam encontrar não apenas a mesma proteção, como a mesma

\footnotetext{
${ }^{10} \mathrm{O}$ caso referido é o BverfGE 47, 46.
} 
representação nos espaços públicos. Negação da existência milita a favor da eliminação da própria existência, como amargamente demonstra o país que mais mata transexuais.

Invisibilizar e reprimir as condutas vinculadas à identidade com o não reconhecimento social da diversidade sexual acirra condutas discriminatórias que se repetem no espaço da escola e a tornam lugar de sofrimento e insegurança. Recente reportagem apresentou dados surpreendentes sobre violência de gênero nas escolas brasileiras, incluindo chocante quantidade de estupros no ambiente escolar. Tal constatação demonstra o quanto o espaço escolar já reproduz o desequilíbrio de gênero e a vulnerabilidade permanente de determinados grupos. Reportagem de $O$ Globo demonstra que a cada cinco dias uma criança é estuprada no espaço escolar no Rio de Janeiro. Os dados causam indignação: 6.222 estupros em dezoito meses, com evidente recorte de gênero ao se constatar que $85 \%$ das vítimas foram meninas e que $40 \%$ tinham menos de doze anos de idade. Aponta a matéria que "levando-se em consideração os locais onde os crimes aconteceram, casos de abusos sexuais em escolas superam os registros em estabelecimentos comerciais, em prédios públicos e meios de transporte" (2017).

A ausência de representação das múltiplas identidades de gênero e o reforço de estereótipos de gênero em materiais didáticos e atividades educacionais reforçam esse cenário, militam contra a função precípua da educação e transformam a escola, que deixa de ser espaço de acolhimento e respeito para se transformar em mais um locus de sofrimento e violência. Desacreditam as potencialidades das meninas, naturalizam o assédio e demais violências sexuais, corroem a função da escola de atuar contra o abuso infantil, reforçam a evasão escolar, alimentam a marginalização e perpetuam outras formas de violência. ${ }^{11}$

\section{CONCLUSÕES POSSÍVEIS}

Observando esses temas em perspectiva, é possível vislumbrar que o espaço escolar pode atuar, resumida, ainda que não exaustivamente, em duas frentes construtivas para os problemas de gênero. Primeiramente, no estabelecimento de acolhida constante para grupos tradicionalmente vulnerabilizados no plano social, permitindo que a escola não apenas se

\footnotetext{
${ }^{11} \mathrm{O}$ fenômeno foi recentemente apontado em matéria jornalística sobre o tema, por Ivan Siqueira, Vicepresidente da Câmara de Educação Básica e relator da Comissão de Direitos Humanos, Orientação Sexual, Identidade de Gênero e Nome Social do Conselho Nacional de Educação (CNE). $O$ Globo. Violência relacionada a identidade de gênero e orientação sexual faz alunos abandonarem escola..
} 
torne espaço seguro para estes grupos, notadamente vinculados a situações de constante evasão escolar; mas também de contraponto necessário ao estabelecido nos espaços privados e públicos que reproduzem de forma acrítica a discriminação baseada em gênero, sem oportunidade do romper a distância de escuta do outro e de convivência, sobretudo da diversidade, que deve compreender um dos pilares de educação inclusiva e rica em experiências. De outra parte, o próprio agir sob novas perspectivas atua, no curto prazo, no questionamento de educandos e educandas ante as condutas conflitantes que vivenciam em outros espaços e possibilita que formem juízos mais completos de diferentes versões.

No médio prazo, permite que esse crescimento se reflita em formação mais tolerante e inclusiva nos espaços de micropoder que vieram a ocupar após conclusão da educação básica formal, que venha a se refletir em benefícios diretos, uma vez que o "outro" não é mais o outro, desconhecido, mas realidade vivida no ambiente escolar, desmistificada, possivelmente se não compreendida na sua essencialidade, compreendida como situação de pessoa com direitos humanos idênticos. No longo prazo, o trabalho empreendido em educação que permita reflexão dos desequilíbrios de gênero, seja nas violações aos direitos de meninas e mulheres, realidade comum e constante em centenas de países e, obviamente, no Brasil; seja na possibilidade de compreensão das diferenças entre gênero, sexualidade, orientação afetiva e sexual como base para respeito à diversidade LGBTT, constroi novas visões sobre direitos humanos.

A discussão sobre "ideologia de gênero" mostra-se uma falácia, pois gênero não constitui escolha ideológica nem aspecto social da construção de identidade externa de performar feminilidade ou masculinidade se confunde com orientação sexual ou afetiva. Tal conceito errôneo não é aleatório. Serve para alimentar ignorância programada que milita a favor do sufocamento e da incompreensão de grupos cujos disseminadores do conceito de gênero como biologia e orientação sexual como escolha a ser direcionada por construção social que frequentemente buscam controlar.

Fortalecer o espaço escolar com estratégias de acolhimento e de reflexão sobre um existir mais tolerante, inclusivo e diverso deve ser o objetivo, que permite ensino de qualidade, pois permite visões mais amplas a fim de compreender o mundo tanto quanto os mundos que compõem a diversidade humana e que não se esgotam na finitude de conceitos binários. 


\section{REFERÊNCIAS BIBLIOGRÁFICAS}

A cada cinco dias uma criança é estuprada dentro da escola no Rio. Extra. Disponível em <https://glo.bo/2vYZyd0>. Acesso em 11 de agosto de 2017.

AQUINO, Felipe. De novo a ideologia de gênero. Disponível em <http://migre.me/wDmPD>. Acesso em 6 ago. 2017.

Bancada evangélica pede alteração do decreto assinado por Temer sobre "ideologia de gênero". Disponível em <http://migre.me/wDr7J>. Acesso em 6 ago. 2017.

BRASIL. Procuradoria-Geral da República. Arguição de descumprimento de preceito fundamental 465/TO. 8 jun. 2017. Disponível em <http://bit.ly/2udzA1B〉. Acesso em 6 ago. 2017.

BRASIL. Supremo Tribunal Federal. Plenário. Ação direta de inconstitucionalidade 4.277/DF. Relator: Ministro Ayres Britto. 5/5/2011, unânime. Diário da Justiça, 14 out. 2011. Disponível em <http://bit.ly/1JBYbBy>. Acesso em 6 ago. 2017.

Católicos dizem não à ideologia de gênero no Plano Municipal de Educação. Disponível em <http://migre.me/wDrkC>. Acesso em 6 ago. 2017.

DWORKIN, Ronald. A virtude soberana. Trad. Jussara Simões. São Paulo: Martins Fontes, 2005.

FURLANI, Jimena. Existe "ideologia de gênero"? Agência Pública - Agência de Reportagem e Jornalismo Investigativo. Disponível em <http://migre.me/wD66i>. Acesso em 6 ago. 2017.

LIONÇO, Tatiana; DINIZ, Debora. Homofobia, silêncio e naturalização: por uma narrativa da diversidade sexual. In: —— (orgs.). Homofobia e educação: um desafio ao silêncio. Brasília: LetrasLivres/Universidade de Brasília, 2009.

Mãe confessa assassinato de filho adolescente no interior de SP. UOL Notícias. Disponível em <http://bit.ly/2uymPz7>. Acesso em 11 ago. 2017.

NAÇÕES UNIDAS. Unesco defende educação sexual e de gênero nas escolas. Disponível em $<$ http://bit.ly/1PIlsXa>. Acesso em 11 ago.2017.

SCHWABE, Jürgen; MARTINS, Leonardo (orgs.). Cinquenta anos de jurisprudência do Tribunal Constitucional Federal alemão. Berlim: Konrad Adenauer Stiftung, 2005.

VAN GUNSTEREN, Herman. Notes in a Theory of Citinzeship. In: BIRNBAUM, Pierre; LIVELY, Jack; PARRY, Geraint (orgs.). Democracy, consensus \& social contract. London: Sage, 1978.

Violência relacionada a identidade de gênero e orientação sexual faz alunos abandonarem escola. O Globo. Disponível em <http://migre.me/wKdie>. Acesso em 4 jun. 2017. 